\title{
Selective Fibrinogen Apheresis for Improvement in Microvascular Hemodynamics
}

\author{
Andre A. Kaplan \\ University of Connecticut Health Center, Farmington, Conn., USA
}

In this issue of Blood Purification, Ramunni's group [1] reports on the short-term effects of fibrinogen apheresis in patients with peripheral arterial disease. Their study was designed to elucidate the immediate post-treatment effect of an abrupt reduction in fibrinogen on the hemodynamics of the lower extremities. The basic concept of the procedure is that fibrinogen is a major determinant of whole blood viscosity and that an apheresis procedure designed to rapidly lower the fibrinogen concentration would improve the flow dynamics of the microcirculation. The symptomatic improvement was impressive, with both total and pain-free walking distance increasing significantly (pain-free WD $60 \pm 52$ vs. 173 $\pm 76 \mathrm{~m}, \mathrm{p}<0.003$; total WD $79 \pm 60$ vs. $194 \pm 80 \mathrm{~m}$, $\mathrm{p}<0.006)$.

These results are certainly noteworthy, but how long would these effects last? The data presented in this paper do not answer that question, but several previously reported data would allow one to make a reasonable prediction. When albumin is used as the replacement fluid during standard, nonselective plasma exchange there is a depletion of fibrinogen [2-5]. Immediately after a single plasma exchange, fibrinogen will be decreased by approximately $60 \%$. Rebound of the fibrinogen level is biphasic, characterized by a rapid initial increase in the first $4 \mathrm{~h}$ after treatment, followed by a slower increase over the next few days [2]. This dual rate of recovery probably represents a relatively rapid initial re-equilibration of extra- vascular stores with the intravascular compartment, followed by a slower rate of resynthesis. Twenty-four hours after treatment, fibrinogen levels are $50 \%$ of initial levels, while it may require $72 \mathrm{~h}$ or more to attain levels which are $75 \%$ of pretreatment values [5]. When multiple treatments are performed over a short period (i.e. three or more treatments per week), the depletion is more pronounced and may require several days for spontaneous recovery [2-5]. Thus, given the relatively short half-life of fibrinogen (approximately 4 days), it would appear that maintaining a time-averaged reduction in the plasma fibrinogen level, and, in so doing, maintaining the beneficial effects on the microvascular circulation, one would have to perform repetitive treatments over a prolonged period of time. Such an experience was documented in a previous report on this selective apheresis technique. In that publication, Koll et al. [6] demonstrated that repeated fibrinogen apheresis could maintain a time averaged fibrinogen level at about $200 \mathrm{mg} / \mathrm{dl}$ in patients whose pretreatment values were approximately $325 \mathrm{mg} / \mathrm{dl}$. This time-averaged reduction was maintained over the course of 12 consecutive treatments. Unfortunately, the publication did not report on the scheduling of the 12 treatments (i.e. daily, weekly, or some other schedule). Thus, given the available evidence, one must conclude that in order to maintain the improved microvascular hemodynamics brought about by this procedure one would require repetitive treatments performed on a continuous basis.

\section{KARGER}

Fax +4161306 1234 E-Mail karger@karger.ch www.karger.com
(C) 2007 S. Karger AG, Basel

0253-5068/07/0256-0402\$23.50/0

Accessible online at:

www.karger.com/bpu

\footnotetext{
Andre A. Kaplan, MD, FACP, FASN

University of Connecticut Health Center

Farmington, CT 06030 (USA)
}

E-Mailkaplan@nso.uchc.edu 
Another major aspect of the Ramunni report is the selective nature of the apheresis made possible by the TheraSorb system. As stated by the authors, use of a selective apheresis device which can selectively remove fibrinogen allows one to make a more precise assessment of the pathophysiologic mechanisms involved and the particular role played by fibrinogen. Selective apheresis, when opposed to nonselective plasma exchange, can also limit the loss of beneficial components of the plasma including albumin, immunoglobulins and clotting factors. Given the wide variation in half-lives of the different immunoglobulins and the various clotting factors [7], one would have to know the required schedule of plasma exchange treatments in order to assess the possible significance of such losses when compared to the selective apheresis technique.

In the past, one could also expect that a selective apheresis device would avoid the elevated costs involved with albumin replacement. This cost benefit of selective apheresis appears to be decreasing. A decade ago, in the United States, 3 liters of 5\% albumin would cost approximately USD 3,000. Currently, however, the charge for this amount of albumin would be closer to USD 300. Thus, the cost of a selective apheresis device would have to be substantially reduced in order to compete with that of standard plasma exchange. But what about efficiency? Ramunni and coworkers report a 50\% decline in fibrinogen after a single treatment using their selective apheresis device. By comparison, a nonselective plasma exchange amounting to a single plasma volume would result in a $60 \%$ decline
[2-5]. Furthermore, Ramunni's group notes a $24 \%$ decline in LDL cholesterol and they refer to previous studies in which selective LDL apheresis resulted in an improvement in acute hearing and vision loss felt to be due to microvascular dysfunction [8-10]. Although the authors speculate that LDL apheresis may be improving microcirculation by its associated removal of fibrinogen, one would have to consider that it is, indeed, the lowering of the LDL cholesterol which is responsible for the improved circulation. Once again, one must note that a single plasma volume exchange with a non-selective system would lower LDL cholesterol by approximately $60 \%$ [11]. Thus, if LDL cholesterol removal played an integral part in the improvement of the microvascular circulation, then standard, nonselective plasma exchange would be far more efficient for its removal.

In conclusion, the report by Ramunni and coworkers documenting the immediate posttreatment effect of selective fibrinogen apheresis on the symptoms of peripheral vascular disease is impressive. What is needed are follow-up data which determine how long the clinical improvement lasts after a single treatment and how often the treatments would have to be performed in order to maintain the improvement. Furthermore, given the possible added benefit of LDL cholesterol removal on the microvascular circulation, one must wonder if a selective fibrinogen removal device would be as efficient as standard, nonselective plasma exchange in which both fibrinogen and LDL cholesterol would be removed more efficiently.

\section{References}

1 Ramunni A, Brescia P, Quaranta D, Plantamura M, Ria R, Coratelli P: Fibrinogen apheresis in the treatment of peripheral arterial disease. Blood Purif 2007;25:404-410.

2 Flaum MA, Cuneo RA, Appelbaum FR, Disseroth AB, Engel WK, Gralnick HR: The hemostatic imbalance of plasma exchange transfusion. Blood 1979;54:694-702.

3 Gelabert A, Puig L, Maragall S, Monteagudo J, Castillo R: Coagulation alterations during massive plasmapheresis; in Sieverth HG (ed): Plasma Exchange. Stuttgart, Schattauer, 1980, pp 71-75.

4 Keller AJ, Chirnside A, Urbaniak SJ: Coagulation abnormalities produced by plasma exchange on the cell separator with special reference to fibrinogen and platelet levels. Br J Haematol 1979;42:593-603.
5 Chrinside A, Urbaniak SJ, Prowse CV, Keller AJ: Coagulation abnormalities following intensive plasma exchange on the cell separator. Br J Haematol 1981;48:627-634.

6 Koll RA, Klinkmann J, Richter WO: RheoSorb: A specific adsorber for fibrinogen elimination in clinical situations with impaired rheology. Artif Organs 2002;26:145151.

7 Kaplan AA: A Practical Guide to Therapeutic Plasma Exchange. Malden, Blackwell Science, 1999.

8 Suckfull M: Fibrinogen and LDL apheresis in treatment of sudden hearing loss: a randomised multicentre trial. Lancet 2002;360: 1811-1817.
9 Ramunni A, Giancipoli G, Guerriero S, Lapenna L, Saracino A, Saliani MT, Capurso A, Sborgia C, Coratelli P: LDL-apheresis accelerates the recovery of nonarteritic acute anterior ischemic optic neuropathy. Ther Apher Dial 2005;9:53-58.

10 Ramunni A, Ranieri G, Giancipoli G, Guerriero S, Ria R, Saliani MT, Sborgia L, Ranieri P, Coratelli P: Is the efficacy of LDL apheresis in ischemic optic neuropathy linked to a reduction in endothelial activation markers? Blood Purif 2006;24:405-412.

11 Kaplan AA: A simple and accurate method for prescribing plasma exchange. Trans Am Soc Artif Intern Organs 1990;36:M597M599. 